\title{
Playing With Daddy: Social Toy Play, Early Head Start, and Developmental Outcomes
}

\author{
Lori A. Roggman, Lisa K. Boyce, Gina A. Cook, \\ Katie Christiansen, and DeAnn Jones \\ Utah State University
}

\begin{abstract}
Research on fathers in Early Head Start (EHS) has provided an opportunity to study fathers from low-income families. We examined father-toddler social toy play in relation to EHS enrollment, fathers' psychosocial well-being, and children's developmental outcomes in a sample of 74 father-toddler dyads. Overall, our results show that father-toddler social toy play was more complex among fathers in an EHS program than among those in a comparison group. Greater complexity in father-toddler social toy play predicted better cognitive and social developmental outcomes for young children, especially in the program group, but it was limited by fathers' psychosocial well-being in the comparison group and by time availability in the program group. Nevertheless, the impact of EHS on father-toddler play suggests that an early intervention that targets father involvement can influence positive father-toddler interactions in ways that enhance early development.
\end{abstract}

Keywords: infant, play, Early Head Start, cognitive development, emotional regulation, father depression

\footnotetext{
This research is part of a longitudinal study of low-income families in a local Early Head Start Research project, supported by grants from the Head Start Bureau, Administration for Children, Youth, \& Families Department of Health and Human Services for local research on Early Head Start (90-YF-0004), a grant from the College of Family Life, Utah State University, a contract with Bear River Early Head Start, Logan, UT, and a subcontract with Mathematica Policy Research, Princeton, NJ. We are grateful to the fathers who participated in our study and to Jerry Cook and Wade Taylor for help with data collection.

Correspondence concerning this article should be addressed to Lori Roggman, Department of Family, Consumer, and Human Development, Utah State University, 2905 Old Main Hill, Logan, UT 843222905. Electronic mail: falori@cc.usu.edu.
}

Fathering, Vol. 2, No. 1, Winter 2004, 83-108.

(C) 2004 by the Men's Studies Press, LLC. All rights reserved. 
RogGman et al.

Children's early development is supported by their interactions with adults, including both fathers and mothers. In recent years, fathers have received increasing research attention regarding their contributions to early child development (Lamb, 1997). However, for children at risk for school failure due to poverty, the potential of fathers for supporting their early development is only beginning to receive research attention. Early intervention programs such as Early Head Start (EHS) are designed to address the problem of inadequate school readiness among children in poverty by promoting development in the earliest years. One strategy for doing this is by increasing the amount and quality of children's interactions with their parents, including their fathers. Research from the national EHS evaluation study has shown that low-income fathers can benefit from early intervention and also that, at least at some research sites, low-income fathers contribute significantly to their children's early development (e.g., Administration for Children, Youth, \& Families [ACYF], 2002; Summers et al., 1999; Shannon, Tamis-LeMonda, London, \& Cabrera, 2002). This study extends those findings by testing the impact of one EHS home-visiting program on specific play interactions between low-income fathers and toddlers that involve sharing toys together. Furthermore, this study examines whether these father-toddler social toy play interactions promote early development.

\section{FATHER-CHILD PLAY}

Much of early development occurs in the context of play interactions with adults. One of these adult playmates is often the father. Father-child play is so central to our existing research and theory about fathers, and perhaps also to our cultural mythology about fatherhood, that a typical father could be called a primary playmate in the same way that a typical mother is called a primary caregiver (Roggman, Boyce, \& Cook, 2001). Play interactions of fathers with their infants and toddlers have been the focus of various approaches to the study of fathers. Compared to mothers, fathers spend more time playing than doing caregiving tasks, interacting primarily as playmates (MacDonald \& Parke, 1986). Furthermore, fathers' play is distinctive (Dickson, Walker, \& Fogel, 1997; Parke, 1981), typically more active and physical than mothers' play, which is typically more verbal and didactic (Goldberg, Clarke-Stewart, Rice, \& Dellis, 2002; Lindsey, Mize, \& Pettit, 1997; Parke, 1981; Roopnarine \& Mounts, 1998). By both the quantity and quality of their play, then, fathers often become the primary and preferred playmates (Clarke-Stewart, 1978; Lamb, 1987; Yogman, 1994).

Father-infant play may offer more than just fun; it may also offer substantial support for early development in multiple domains. The consistent quantitative and qualitative distinctions between fathers and mothers in their play with infants suggest that father play may have a special role in supporting early development by providing greater variation in play experiences. These play experiences may provide unique sources of both cognitive stimulation and emotional support for infants as they explore their environments and acquire knowledge and skills. Several studies have shown an association between father involvement and engagement with infants and toddlers and the children's development of cognitive competence (Nugent, 1991; Wachs, Uzgiris, \& Hunt, 1971; Yogman, Kindlon, \& Earls, 1995). Regarding 
social competence, father play is associated with better child peer relations and emotional regulation (Pettit, Brown, Mize, \& Lindsey, 1998; Roberts, 1998). Recent research on attachment suggests that the support fathers offer to toddler exploratory play is critical in the development of secure attachment through childhood, a central aspect of social development (Grossman et al., 2002). Taken together, these studies strongly suggest an important role for father-toddler play interaction in early development. Because fathers are often preferred as playmates, because they play more, and because their play interactions can be unique, one would expect that individual variations in the quality of father-toddler play would make important contributions to early social and cognitive development.

Although fathers play more physically than mothers, they also do many of the same kinds of things in play that mothers do. Some studies have shown that the relative frequency of different types of play differ between mothers and fathers (Yogman, 1981), yet most types of parent-infant play occur with both fathers and mothers and with similar amounts of affection, object play, physical play, and conventional play interaction (Goldberg et al., 2002; Laflamme, Pomerleau, \& Malcuit, 2002). When fathers play with infants and toddlers, they may do more rough and tumble play, but they also are likely to spend time playing together with toys (Goldberg et al., 2002). Playing together with toys, as seen in studies of mother-infant play, typically requires sharing those toys, and sharing a focus on the same object provides a valuable context for early language and social development (Charman et al., 2001; Goldfield, 1987; Jacobson, 1981; Laasko, Poikkeus, Eklund, \& Lyytinen, 1999; Newland, Roggman, \& Boyce, 2001; Saxon, Colombo, Robinson, \& Frick, 2000). In social play interactions that include toys, exchanges of objects offer a context for shared meaning, essential for language and cognitive development, and turn taking, essential for communication and appropriate social interaction (Newland et al., 2001; Mundy, Kasari, \& Sigman, 1992).

\section{PREDICTORS OF FATHER-INFANT PLAY}

Father involvement in play is likely to be related to several other parenting behaviors seen during play that have been shown to benefit early development, such as cognitive stimulation, sensitivity, and warmth or positive regard. Most of this research has been done with mothers but would be expected to apply to fathers' play as well. When mothers expand their children's horizons by providing new information and ideas, they thereby stimulate their children's early language and cognitive development (e.g., Graul \& Zeece, 1990; Tamis-LeMonda \& Bornstein, 1989, 1990). When mothers express emotional warmth and sensitivity to their children's cues and let their children take the lead in play, they thereby contribute to their children's positive developmental outcomes (Diener, Nievar, \& Wright, 2003). When fathers show these aspects of supportiveness during play, they too contribute to early cognitive, language, and social development (Black, Dubowitz, \& Starr, 1999; Grossman et al., 2002). Fathers and mothers may show these qualitative aspects of play in different quantities. Nevertheless, the aspects of mothers' behavior during play that affect children's early development may be every bit as influential when they characterize father behavior during play. A recent study of low-income fathers 
RogGMAN et al.

showed that, indeed, fathers' responsive and didactic behavior during play is strongly related to children's early cognitive development (Shannon et al., 2002).

Other factors related to variability in father-infant play interactions may be similar to the factors that influence variability in mother-infant interactions. For example, extensive research has shown that maternal depression affects the quality of mother-infant interactions (Albright \& Tamis-LeMonda, 2002; Carter, Garrity-Rokous, Chazan-Cohen, Little, \& Briggs-Gowan, 2001; Hoffman \& Drotar, 1991; Jameson, Gelfand, Kulcsar, \& Teti, 1997; Leadbeater, Bishop, \& Raver, 1996). The work of Field and colleagues specifically suggests that even mildly depressed mothers show less positive and animated facial expressions when interacting with their children (Malphurs, Field, Pelaez-Nogueras, \& Martinez, 1997) and that the interactions of depressed mothers with their children have negative effects on children's behavior throughout infancy and childhood (Field, 1998, 2000).

The psychosocial health of fathers may similarly affect their interactions with their infants, including play. In fact, recent research has shown that father depression is related to less involvement in activities with their infants (Roggman, Benson, \& Boyce, 1999). More specifically, fathers who are depressed are less likely to play with their infants and more likely to interact negatively (Lyons-Ruth, Wolfe, Lyubchik, \& Steingard, 2002). Although there has been less research on the effects of father depression than the effects of mother depression, father depression would be expected to inhibit play interactions similarly to mother depression by decreasing affective responsiveness generally or to infant cues more specifically. Because these affective responses are part of the supportiveness of play interactions, father depression would be expected to be correlated with less supportive behaviors by fathers during play with their infants. Indeed, it may be particularly important to study these links in fathers, because father interactions with older children have been shown to be even more influential on child outcomes than mother interactions when depression is taken into account (Jacob \& Johnson, 2001, 1997; Johnson \& Jacob, 2000).

Other dimensions of fathers' psychosocial health that influence either play interactions with infants or child outcomes include general stress (Goldberg et al., 2002) as well as specific stress related to parenting (Magill-Evans \& Harrison, 2001). In a study of fathers of both healthy and medically compromised children, initial parent stress was related to less responsive and less positive interactions with their children a year later (Darke \& Goldberg, 1994). Concurrent stress was not, however, related to behavior during interactions with children, indicating that stress experienced early in a child's life may have a formative effect on later relationships and interaction patterns.

Finally, the quality of father involvement with their children, including their play interactions, depends to some extent on the amount of time they actually spend with their child. For at least some groups of fathers, those who work more hours per week spend less time with their infants and also report less involvement in activities with them (Crouter, Perry-Jenkins, Huston, McHale, 1987; Roggman et al., 1999). In addition to the amount of time available, father-infant interactions may also be affected by other relationships in the family. The quality of the relationship between the parents, whether they experience a lot of conflict or not, may also affect how fathers interact and play with their infants (Doherty, Kouneski, \& Erickson, 1998). 
PLAYING WITH DADDY

\section{INTERVENTIONS}

If father play has the potential to promote children's optimal development as early as infancy, and if father play is vulnerable to the negative effects of poor parenting skills and poor psychosocial well-being, it may be important to develop appropriate interventions to support positive father-infant play. Some programs have been successful at promoting toy play interactions to promote early cognitive development. One such program is the Parent-Child Home Project in which low-income families with young children were given toys and books designed to promote parent-child conversation, thereby increasing young children's verbal ability (DeVito \& Karon, 1990; Levenstein, Levenstein, Shiminski, \& Stolzberg, 1998). Long-term results show that children in this program had higher cognitive test scores through adolescence and higher rates of high school graduation than children from a comparison group.

Some intervention programs have focused directly on promoting fathers' involvement with infants and increasing their knowledge about infant development (Mahoney, Wiggers, \& Lash, 1996; Myers, 1982; Pfannenstiel \& Honig, 1995), but these studies have not examined fathers in more comprehensive programs aimed at the infants themselves. For programs aimed at promoting development of children from low-income families, it may be especially important to support father-infant play because other research has shown that fathers of lower socioeconomic status are less likely to play with their infants (Gerson, 1993; Grossman, Pollack, \& Golding, 1988). Father involvement in Head Start, aimed at preschool age children from lowincome families, has resulted in positive impacts on children (Fagan \& Iglesias, 1999).

The EHS program, directed at infants and toddlers, could both directly and indirectly promote positive father-infant interaction. In many EHS programs, one strategy for promoting infant development is by striving to improve the quality of parent-infant interactions. Overall, EHS programs appear to be successful at doing this for fathers; the national evaluation, testing the impact of a variety of EHS programs, showed that fathers in the program group spanked less and were less intrusive in their interactions with infants (ACYF, 2002).

Many EHS programs explicitly target father involvement as a program objective to increase both the amount and quality of father-child interaction. These EHS programs typically offer special activities for fathers to attend with their infants and toddlers, additional opportunities for fathers to learn about infant development, and ways for fathers to connect with each other (Raikes et al., 2000). Father-infant play may increase in quantity and in quality as a result of these experiences for several reasons. First, fathers may learn more about how playing with infants and toddlers can promote early development by facilitating the beginnings of skills needed for communication, thought, and emotional regulation. Second, fathers may learn that paying attention to the child's cues and letting the child take the lead can make play and other interactions more enjoyable for both of them and even more helpful for the child's early development. Third, fathers may derive support from their interactions with program staff and with other fathers that helps them become more at ease playing with their infants and toddlers. Finally, father play may be indirectly supported 
RogGMAN et al.

through the many health, mental health, and social services provided by EHS to the entire family.

In our local EHS program, the site for this study, initial program objectives included providing a support framework for parents, including fathers, to enhance their ability to support and nurture their children. This semi-rural program delivered services primarily through home visiting and encouraged parents to play with infants and respond sensitively to infants' cues. Fathers were targeted through specific planned activities for fathers as well as through an emphasis on scheduling home visits when fathers could be present. The program hired a "father involvement specialist" who planned events and activities for fathers, developed handouts describing developmentally appropriate father-infant activities, and provided additional resources to help other program staff involve fathers in the program.

This particular program, then, planned and implemented strategies from the beginning to help fathers interact more with their infants, to learn about child development in multiple contexts, and to form social networks with other fathers. Fathers commented that the program helped them "make simple activities fun" and "understand developmental stages and what is normal." Nevertheless, this program, like many other programs, faced several challenges trying to involve fathers. Fathers' work schedules and other commitments made it difficult to find a time for home visits when fathers could be present. In addition, some fathers were reluctant to get involved in a program perceived as targeting mothers and infants.

\section{PURPOSE OF THIS STUDY}

By testing the impact of this EHS program on the social toy play behavior of these fathers, we hoped to further our understanding of the potential for an early intervention program to foster father-infant play. By examining father-infant play in relation to children's developmental outcomes, we hoped to clarify how father-infant social toy play can promote children's early cognitive and socio-emotional development.

The purpose of this study was threefold: first, to test the impact of EHS on father-toddler social toy play; second, to explore other correlates and predictors of father-toddler social toy play; and third, to examine how father-toddler social toy play is related to children's developmental outcomes. We expected that an EHS program impact on father-toddler social toy play would be seen by age two, that predictors and correlates of any impacts would also be seen by age two, and that child outcomes related to father-toddler social toy play would be evident in their development by age two and remain evident at age three. Working from this model, we selected specific age points for predictors and outcomes. We assessed father-toddler social toy play when the toddlers were two years old. For predictors, we selected measures from the earliest time at which we had the proposed psychosocial measures from fathers, 10 months, in addition to a time concurrent with our initial observations of father-toddler play at 24 months. For child outcomes we selected measures from the two outcome times identified in the national study, 24 and 36 months.

The following research questions were addressed. Does EHS have an impact on father-toddler social toy play? Is that impact evident by the time the child is 24 months old? Are father-infant social toy play interactions related to other father or 
child characteristics? What behavioral and psychosocial characteristics of the father at 10 and 24 months, such as depression, parenting stress, time availability, and relationship with mother, are related to father-toddler social toy play in both the EHS and comparison groups? What child characteristics such as earlier development and gender are related? Is father-toddler social toy play related to children's cognitive, language, and emotion regulation outcomes at 24 and 36 months in both groups?

\section{METHODS}

This local EHS study, conducted in a rural and semi-rural area of the United States, involved a longitudinal experimental and correlational design with data collected from parents and children at multiple time points. All participants were qualified applicants for EHS who met federal poverty guidelines. After eligibility was confirmed, participant families were randomly assigned to either the EHS program or a comparison group. Data analyzed for this report were only from families who applied for this EHS program and identified a father who was willing and available to participate in the research.

Fathers in families randomly assigned to the EHS program had opportunities for several kinds of program involvement. All fathers were provided with handouts describing and assigning specific weekly activities to do with their toddlers. Fathers were encouraged to attend, with the mother and target child, weekly "socialization" groups in which parents and children played together. Home visits included fathers when they could be scheduled to do so, and the activities focused on getting parents, both mothers and fathers, actively playing with their toddlers during the visits. Home visitors used several strategies to involve fathers: They reinforced fathers' involvement, asked fathers to do specific tasks, directed fathers' attention toward children, provided space and materials for fathers to join in easily, pointed out children's interest and response to fathers, encouraged fathers to act as role models, and got to know fathers as individuals. When fathers could not be present, home visitors encouraged mothers to include them in planned activities with children at other times. Other program activities targeting fathers included social events that encouraged the whole family to attend, such as holiday celebrations, events especially for fathers with their children, such as father-child breakfasts, and events specifically for fathers to socialize with each other, such as Monday Night Football watching. Fathers in the comparison group may have had access to similar activities in the community, but there were no other known public programs for infants and toddlers that explicitly targeted fathers in this geographical area (within 50 miles).

Data collection occurred at child ages 10, 14, 24, and 36 months. Fathers were interviewed at each time using various measures. At 24 months, father-child play interactions were videotaped for later coding of specific kinds of behaviors. Children's developmental skills were tested at home during separate assessments at 14, 24 , and 36 months. For data collected in family homes, time in the homes ranged from 90 minutes to three hours when observations were included and ranged from 30 minutes to one hour when only interviews were included. Family background information was provided on application forms from each family. 
RogGMAN et al.

\section{PARTICIPANTS}

Participants in this study included low-income fathers or father figures of 74 children in a local EHS study who were willing and available to participate in in-home observational research when their child was 24 months old. Our local EHS research sample $^{1}$ originally included 196 families who applied for and were eligible for EHS at our site, and of those, 148 families had a father consistently identified, 74 of whom participated in this observational research.

Of the 74 participating fathers, $47 \%$ were in families randomly assigned to the EHS program, $97 \%$ were white and married to or living with the mother and child, 95\% were the biological father of the child, $90 \%$ had completed high school, and $70 \%$ were employed at least 40 hours/week while $51 \%$ of their children's mothers were at home full time. Family annual incomes averaged around $\$ 10,000$ per family and $\$ 3,000$ per family member, with $90 \%$ having $\$ 4,500$ or less per year per family member (calculated per family member because of family size range in this sample). Of the 74 children, $47 \%$ were male. Of the participating fathers, 35 were in the EHS program group and 39 were in the comparison group. In the program group, 18 (51\%) of the children were male; in the comparison group, 17 (44\%) of the children were male. For 63 of the participating fathers, 31 in the program group and 32 in the comparison group, early data from application forms were available for comparing fathers in families subsequently randomly assigned to the EHS program versus the comparison group. Statistical comparisons indicated that there were no significant differences between research participant fathers in the program and comparison groups.

Of the 148 fathers identified by the mothers at application and later, 40 did not participate because they had moved out of the area or had conflicting schedules not allowing in-home assessment, and 34 refused or could not be located. Another seven families had different persons identified as a father or father figure later in the study who were not included in the analyses reported here. Differences between the fathers who participated and those who did not indicate that research participants, compared to those who were unavailable or unwilling to participate, reported higher levels of education (13.8 vs. $12.5 \mathrm{yrs}), t(127)=-3.7, p=.00$, and less parental distress at 10 months (1.8 vs. 2.0 on a parenting distress scale), $t(106)=2.1, p=.04$.

\section{PROCEDURES}

Three basic procedures were used to collect data in this study: parent-child observation, child standardized testing, and parent interviews (in homes or by telephone). Most data collectors were hired and trained to do all of these procedures, although some were hired and trained to do parent interviews only. For the observations, fathers and children were videotaped in a semi-structured play situation for which they were asked to play with toys in three bags using standardized instructions (Berlin, Brady-Smith, Brooks-Gunn, 2002). For child standardized testing, test administration was practiced, videotaped, and checked by an independent observer to ensure accuracy in wording, toy placement, timing, and scoring.

For parent interviews, data collectors were audiotaped for consistency checks to ensure identical wording of questions. All data collectors were supervised to ensure 
that they continued to accurately follow procedural protocols. Interviews at 10 months were conducted mostly by telephone, but occasionally in fathers' homes when they did not have a telephone. Interviews at 14, 24, and 36 months were conducted mostly in fathers' homes, but sometimes by telephone to accommodate fathers' work schedules.

\section{MEAsures}

Three types of measures were used to address the research questions: coded observational measures, standardized child assessment measures, and father interview measures. Together these measures provide indications of the quality of parent-child play, children's developmental outcomes, and fathers' psychosocial well-being and other characteristics.

Coded observational measures. Parent-toddler social toy play and other parent behaviors were measured by observational coding of videotaped play sessions. Social toy play was coded locally, and other parent behaviors during play were coded nationally. However, fathers were not part of the national study at 14 months, so local coders established reliability with the national coders on the parent behavior codes and then coded 14-month father behavior locally. National coding was done at Columbia University as part of the national EHS Research and Evaluation project.

Social toy play was measured by coded observations using a global rating scale developed specifically for this study. A rating from 1 to 7 of the complexity of shared toy interactions was made after the coder viewed the entire 10-minute father-child play segment. Ratings were based on both quantity and quality of assertions (initiating an exchange of toys, conversation, or game), responses (responding to the others' assertions), and sequences (a simple exchange that goes beyond a simple assertion and response to an additional or expanded response). A low rating (1) was defined as "very few assertions, most not responded to, and long periods of no interaction while each plays with his or her own toys or simply watches the other without talking." Occasionally, a toddler or father may appear to offer a toy, but the other does not respond. A moderate rating (4) was defined as "more than half of assertions are responded to but mostly in simple (two-step) exchanges and conversations." For example, the toddler hands the father a piece of pretend pizza, and the father pretends to eat it. A high rating (7) was defined as "complex sequences sustained for several steps in which toys are shared back and forth, conversation continues, and games are played."

High ratings required an extension of simple turn taking, to include additional conversation, play, or the return of the toy beyond toy exchanges. In a complex exchange, for example, the toddler hands the father a toy phone, the father accepts the phone and says "hello" and then says "it's for you" and hands it back to the child, who accepts the toy phone and vocalizes into it. Other kinds of responses to a toy that do not require pretending also qualified as a complex sequence. For example, a complex sequence would be coded when a father hands a toddler a toy and the toddler simply bangs it on the floor and then hands it back to the father. The duration of these social toy play interactions was not timed, but the codes were defined 
RogGman et al.

to take into account the frequency of toy exchanges. Thus the coding scheme was qualitative in nature but took some account of the quantity of play. Other aspects of the father's behavior, such as responsiveness or positive affect, were not used to code social toy play.

Other parent behavior was coded from the videotapes both locally and nationally using codes developed at Columbia University for the national EHS Research and Evaluation project. Three behaviors representing aspects of parent supportiveness of play were coded on a 1-to-7 scale with 7 representing high-quality behavior. These measures and detailed coding procedures are presented in full detail in Berlin et al. (2002). Parent Sensitivity was defined as the degree to which the parents' interaction was sensitive and child focused (e.g., the father did not impose his own agenda but allowed the child autonomy), degree of praise and encouragement, and how well there was a balance between giving support and allowing independent exploration. Cognitive Stimulation was defined as the parent's ability to enhance perceptual, cognitive, and language development. This included the parent's awareness of the child's developmental level and the ability to bring the child above that level. Positive Regard was defined as the parent's expressions of love, respect, and/or admiration for the child. This included the quality as well as quantity of behaviors such as hugging, smiling, praising, and showing clear enjoyment of the child. These three ratings were inter-correlated ( $r \mathrm{~s}=.59-.62$; Berlin et al., 2002) and therefore combined into one scale of Supportiveness for the national study (alpha $=.82$; Berlin et al., 2002). In our local data, the internal consistency among these items was high at both ages (14 mo alpha $=.76 ; 24$ mo alpha $=.78$ ) so we also combined them into one scale of Supportiveness.

Reliability of the national coding measures was established at $85 \%$ agreement and maintained at 90\%, allowing for a one-point difference in scores (ACYF, 2002). Local reliability for both coding schemes was established as soon as paired coders viewed five consecutive videotapes with $100 \%$ agreement $($ Kappa $=1.0)$, allowing for a one-point difference in scores - the same criterion used for the national study. To maintain consistency during coding, coding teams met regularly to solve problems and prevent coding drift, and every fourth videotape was checked for reliability, which was maintained at more than $95 \%$ agreement and .90 Kappa, allowing for a one-point difference in score. To minimize bias, coders were "blind" to the group status of the families (i.e., program or comparison).

\section{Standardized Child Assessment Measures}

Cognitive development and language development were assessed directly using the Bayley Scales of Infant Development, second edition (BSID-II; Bayley, 1993) at 14, 24, and 36 months. The BSID-II is a commonly used standardized tool for assessing children's cognitive and motor development. Both internal consistency (.88) and interrater (.96) standardized reliability scores were provided by the authors for the test's total cognitive score. For the EHS research, Bayley items were selected for each age group. For our local sample, internal consistency of the items in total cognitive score was adequate at all three ages, 14-month alpha $=.79,24$-month alpha $=.85,36$-month $a l p h a=.99$. A language development score derived from a subset of 12 items was cal- 
culated at 24 and 36 months for the national study, cross-age alpha $=.86$, and used for our local sample as well; 24-month alpha $=.98,36$-month alpha $=.97$.

Emotional regulation was calculated from observational ratings on the Behavior Rating Scales of the BSID-II used to code children's behavior during the testing session. Rating items used for the Emotional Regulation score included fearfulness/trust, energy/activity level, adaptation to transitions, and hypersensitivity. Reliability for the emotional regulation scale included published alpha $=.88$, national study alphas $=.90-.92$, local study 14-month alpha $=.90,24$-month alpha $=.92,36-$ month alpha $=.93$.

\section{FAther Interview Measures}

Several background questions were asked at application about fathers' marital status, ethnicity, residence, paternity, education, age, and family income.

Fathers' psychosocial well-being was assessed in the parent interview. Depression was assessed as part of comprehensive interviews with fathers when their infants were 10 and 24 months old. The measure of depression was the Center for Epidemio logical Studies Depression scale (CES-D; Radloff, 1977). This scale contains 20 items describing symptoms of depression. Each description begins with the phrase "During the past week" and then describes a symptom of depression such as "my sleep was restless," or "I was bothered by things that usually don't bother me." Fathers responded to each description using a 1 to 4 Likert scale to rate how frequently they had felt that way during the past week. The scale items have high internal consistency, yielding a Cronbach's alpha of 90 (Hall, Williams, \& Greenberg, 1985). For our sample, Cronbach's alphas at the two time points ranged from .87 to .91 .

Parental distress and dysfunctional interaction, other aspects of father psychosocial well-being, were measured using two subscales of the Parenting Stress Index/Short Form (PSI/SF; Abidin, 1990) in interviews with fathers when their infants were 10 and 24 months old. These subscales assess stress associated with different aspects of parenting. The PSI/SF was developed originally from a longer form of the PSI using exploratory factor analysis. Fathers responded to questions using a five-point Likert scale with responses ranging from "strongly agree" to "strongly disagree." Sample items include: "You are less interested in people than you used to be," from the distress subscale, and "Your child rarely does things for you that make you feel good," from the dysfunctional interaction subscale. Reported internal consistency for the subscales range from .76 to .86 (Abidin, 1990). For our sample, Cronbach's alphas at the two time points for the two subscales ranged from .71 to .83 .

Family conflict was measured during the 10 -month interviews by nine items from the Dyadic Adjustment Scale (DAS; Spanier, 1987) selected for use in the EHS national study using seven (of 10) items from the original dyadic satisfaction subscale and two (of five) from the original dyadic cohesion subscale. The items ask respondents to rate the frequency of marital conflict behaviors or events using a five-point Likert scale ranging from "all the time" to "rarely or never." Example items included "about how often do you and your spouse: discuss or consider divorce," "quarrel," "get on each other's nerves," and "calmly discuss an issue that has been bothering you?" Spanier's original DAS reported internal consistency 
RogGman et al.

alphas for the dyadic satisfaction and cohesion subscales, from which these items were taken, as .94 and .81 , respectively. For our sample, Cronbach's alpha at 10 months was .75.

Because of the integration of national and local data collection in this study, fathers were asked in different ways at different times about the amount of time spent with their child. At 10 months, fathers were asked how often they did various activities with their child and responded on a seven-point scale from "several times per week" to "never." These time ratings were averaged across activities. At 24 months, fathers were asked how many hours they spent with their child per weekday and weekend day, and a weekly total was calculated. The two measures were not correlated, $r(46)=-.03$.

\section{RESULTS}

This study used an experimental and correlational design. Because families were randomly assigned to either an EHS group or a comparison group, the impact of EHS could be tested directly. Descriptive and relational questions relied on correlational analyses of independent variables that were not experimentally controlled. Data analysis strategies varied by research question. Analyses included tests of mean differences between program and comparison groups and correlational analyses of relations between father-toddler social toy play and other relevant variables. First, the impact of the local EHS program on fathers' social toy play with their toddlers was tested. Next, father-toddler social toy play was examined in relation to other father behavior, fathers' psychosocial well-being, and children's development. Finally, we tested multivariate models of the influence of father-toddler play on children's developmental outcomes, controlling for children's earlier development.

In general, our results show that fathers do engage in complex social toy exchanges during play with their toddlers. The overall average social toy play rating score, 3.8 on the 1-to-7 scale, indicates that more than half of social initiations of toy sharing or conversation were responded to, but few complex sequences were observed that moved beyond simple assertions and responses. No one was coded as a 1, defined as few assertions, indicating that all 74 of the father-toddler pairs were initiating social toy play by showing and offering toys.

\section{IMPACT OF EHS ON FATHER-TODdLER PLAY}

Family enrollment in EHS was significantly and positively related to father-toddler social toy play at 24 months. A direct test comparing the fathers in EHS to fathers in the comparison group showed that fathers whose families were enrolled in this early intervention program, compared to those who were not, engaged in more complex social play interactions at 24 months, $F(72)=6.27, p=.01$. Fathers' average social toy play scores were $4.1(S D=.87)$ for the program group versus $3.6(S D=.82)$ for the comparison group. A correlation between the father-toddler social toy play rating and a dummy-coded program versus comparison variable represents an estimated effect size of .28. 
PLAYING WITH DADDY

\section{Relations Between Father-Toddler Play and Other Father OR CHILd Characteristics}

Table 1 shows correlations, for the total sample and for the EHS and comparison groups separately, between 24-month father-toddler social toy play and other father behaviors observed during play with their toddlers. Father supportive behavior during play, observed both earlier at 14 months and concurrently at 24 months, was significantly and positively related to father-toddler social toy play. The magnitude of these correlations indicates that the constructs of supportiveness and social toy play are related to each other but are not the same thing. Fathers who engaged in more complex social toy play interactions with their toddlers were also likely to be more sensitive, positive, and cognitively stimulating, the defining behaviors of supportiveness, but the variability of father-toddler social toy play was not entirely explained by these other positive behaviors.

Several father psychosocial predictors were significantly related to father-toddler social toy play. Correlations in Table 1 show that fathers were more likely to engage in complex social interactions with their toddlers during play when they reported lower levels of stressful or dysfunctional interactions with their toddlers and, especially for the comparison group, fewer symptoms of depression. In the EHS group, social toy play was more complex when fathers spent more time with their children and had less conflict with the child's mother. Other father characteristics of age, education, and parenting distress were not related to father-toddler social toy play. Children's earlier development and gender were not related to social toy play.

To sort out the independent effects of father characteristics and the EHS program, we tested a regression model that included fathers' depression, dysfunctional interaction, and supportive behavior along with a dummy-coded program factor (coded 0,1 ). In the total sample, as shown in Figure 1, father supportiveness as well as EHS program enrollment predicted father-toddler social toy play, but the psychosocial factors did not have a statistically significant effect when both program and supportiveness were included in the model, Adjusted $R^{2}=.28 ; F(4,55)=3.7, p$ $=.000$. Also shown in Figure 1 are the results of regression analyses done separately for the EHS program group and the comparison group. Because bivariate correlations differed for fathers in the EHS and comparison groups, we tested separate regression models for each group including father depression, dysfunctional interaction, and supportive behavior as predictors. In the EHS group, when analyzed separately, fathers' depression made no independent contribution to play above and beyond dysfunctional interaction and supportiveness, Adjusted $R^{2}=.14 ; F(3,24)=$ $2.5, p=.089$. In the comparison group, in contrast, fathers' depression made a significant independent contribution to father-toddler social toy play even when the model also included parent-child dysfunctional interaction and father supportiveness, Adjusted $R^{2}=.28 ; F(3,28)=5.1, p=.006$. This difference between the two separate groups indicates that EHS program enrollment may have buffered, or moderated, the effect of fathers' depression on father-toddler social toy play.

To further examine whether the EHS program moderated the relation between depression and play, we examined the effect of an interaction term, program by depression (with both variables centered), in another set of regression models. In a 
RogGman et al.

Table 1

Correlations of Father and Child Characteristics with Father-Toddler Social Toy Play at 24 Months

\begin{tabular}{|c|c|c|c|}
\hline $\begin{array}{l}\text { Correlates of } \\
\text { Father-Toddler Social Toy Play at } 24 \text { months }\end{array}$ & $\begin{array}{l}\text { Total } \\
\text { Sample }\end{array}$ & $\begin{array}{l}\text { EHS } \\
\text { Group }\end{array}$ & $\begin{array}{l}\text { Comparison } \\
\text { Group }\end{array}$ \\
\hline \multicolumn{4}{|l|}{ Father behavior } \\
\hline Supportiveness during play at 14 months & $.29 *$ & .05 & $.42 *$ \\
\hline Supportiveness during play at 24 months & $.41 * *$ & $.47 * *$ & $.34 *$ \\
\hline \multicolumn{4}{|l|}{ Father background characteristics } \\
\hline Father age at program enrollment & -.08 & -.05 & .00 \\
\hline Father years of education at 24 months & -.05 & -.06 & -.06 \\
\hline \multicolumn{4}{|l|}{ Father psychosocial well-being } \\
\hline Depression at 10 months & .02 & -.27 & .22 \\
\hline Depression at 24 months & $-.29 *$ & -.06 & $-.51 * *$ \\
\hline Parenting distress at 10 months & -.03 & -.30 & .12 \\
\hline Parenting distress at 24 months & -.05 & .10 & -.19 \\
\hline Parent-child dysfunctional interaction at 10 months & $-.29 *$ & $-.33+$ & -.25 \\
\hline Parent-child dysfunctional interaction at 24 months & $-.25 *$ & -.24 & -.23 \\
\hline \multicolumn{4}{|l|}{ Father Time Availability } \\
\hline Time spent doing activities with child at 10 months & .03 & .16 & -.08 \\
\hline Total weekly time with child at 24 months & $.24+$ & $.43 *$ & .07 \\
\hline \multicolumn{4}{|l|}{ Father Relationship with Mother } \\
\hline Marital Conflict at 10 months & -.08 & $-.36+$ & .11 \\
\hline \multicolumn{4}{|l|}{ Earlier Child Development } \\
\hline Cognitive development at 14 months & .15 & .24 & .08 \\
\hline Emotional regulation at 14 months & -.11 & -.17 & .02 \\
\hline \multicolumn{4}{|l|}{ Child developmental outcomes } \\
\hline Cognitive development at 24 months & $.40 * *$ & $.49 * *$ & .31 \\
\hline Cognitive development at 36 months & $.28^{*}$ & .26 & .15 \\
\hline Language development at 24 months & $.33 * *$ & $.37 *$ & .27 \\
\hline Language development at 36 months & $.28 *$ & $.37+$ & .11 \\
\hline Emotional regulation at 24 months & $.40 * *$ & $.44 * *$ & $.43 * *$ \\
\hline Emotional regulation at 36 months & .24 & .21 & .24 \\
\hline
\end{tabular}

$+p \leq .10 . * p \leq .05 . * * p \leq .01$.

complex model with multiple predictors, Adjusted $R^{2}=.29 ; F(5,54)=5.8, p=.000$, but the interaction term did not approach statistical significance, Beta $=.16, p=.16$, perhaps because of the variance accounted for by supportiveness in this relatively small sample, Beta $=.37, p=.002$. In a simplified model with only depression, program, and the interaction term predicting play, the interaction of program and depression approached statistical significance, Beta $=.22, p=.07$, and the overall model remained significant, Adjusted $R^{2}=.18 ; F(4,57)=5.4, p=.002$. An examination of the separate groups confirmed that father depression was a negative predictor 

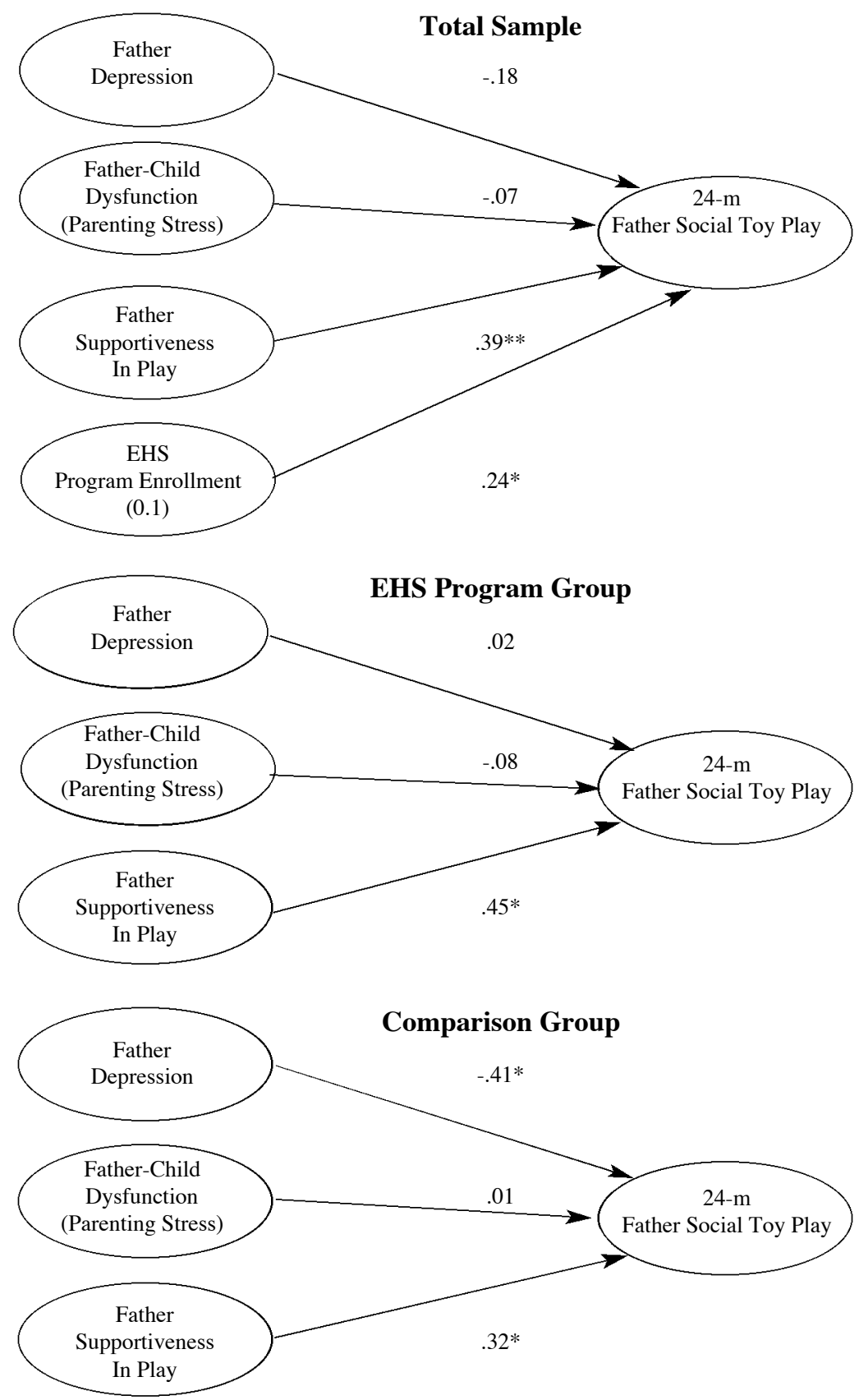

Figure 1. Standardized coefficient estimates for predictors of father-toddler social toy play.

${ }^{+} p \leq .10 .{ }^{*} p \leq .05 .{ }^{* *} p \leq .01$. 
RogGman et al.

of father-toddler social play only in the comparison group, as evident in the bivariate correlations. Taken together, the different correlations and regression models for EHS and comparison groups analyzed separately and the program by depression interaction, our results show that EHS buffered the negative effects of father depression on father-toddler social toy play.

\section{Relations Between Father-Toddler Play AND CHILDREN's DEVElopMENTAL OUTCOMES}

Table 1 shows correlations between father-toddler social toy play and children's developmental outcomes. Father-toddler social toy play was significantly and positively related to children's cognitive development, language development, and emotional regulation at both 24 and 36 months. To explore the additive effect of fathertoddler social toy play on children's development beyond earlier child functioning, multiple regression models were tested for each developmental outcome at 24 and 36 months controlling for children's test scores on the same instrument at the previous age (except we used 14-month MDI cognitive scores to predict 24-month language because a 14-month language subscale was not available).

Tables 2 and 3 show estimates from multiple regression analyses with 24-month and 36-month outcomes predicted from children's previous functioning and fathertoddler social toy play. Children's previous functioning was a significant predictor for their later development in all three domains at 24 months and for cognitive and language development at 36 months. Father-toddler social toy play remained significant in the models predicting cognitive development, language development, and emotional regulation at 24 months but was a weaker predictor, although it approached significance, for all three outcomes at 36 months. Thus, the complexity of father-toddler social toy play contributed to children's development above and beyond the children's earlier development. An examination of possible moderator effects of the EHS program indicated no further contribution of the program, either directly or as a moderator.

In summary, these fathers and their toddlers shared toys mostly in simple exchanges and conversations in which one initiated the interaction and the other responded. The complexity of these social toy play exchanges at 24 months was greater for those enrolled in EHS than for those in a comparison group. Father-toddler social toy play at 24 months was related to earlier and concurrent ratings of father supportiveness during play. These relations were moderate, suggesting that the constructs of supportiveness during play and actual play interactions are related but not the same thing. Fathers who engaged in more complex social toy play also reported less stressful interactions with their toddlers, but other father characteristics that predicted social toy play were different for the EHS and comparison group fathers. Comparison group fathers' play was more complex if they were not depressed. In the EHS group, depression did not affect play, apparently buffered by program enrollment. For EHS fathers, social toy play was more complex if they spent more time with their children. Children's cognitive and language development and emotional regulation were predicted by father-toddler social toy play beyond what could be predicted by earlier child functioning. 
Table 2

Regression Models Predicting Developmental Outcomes at 24 Months

\begin{tabular}{|c|c|c|c|}
\hline & $B$ & $S E B$ & Beta \\
\hline \multicolumn{4}{|l|}{ Predicting cognitive development ${ }^{\mathrm{a}}$} \\
\hline MDI score at 14 months & .67 & .15 & $.43^{* *}$ \\
\hline Father-toddler social toy play & 5.8 & 1.8 & $.34^{* *}$ \\
\hline \multicolumn{4}{|l|}{ Predicting language development ${ }^{\mathrm{b}}$} \\
\hline MDI score at 14 months & .009 & .03 & $.32^{* *}$ \\
\hline Father-toddler social toy play & 1.0 & .42 & $.28^{*}$ \\
\hline \multicolumn{4}{|l|}{ Predicting emotional regulation ${ }^{\mathrm{c}}$} \\
\hline Emotional regulation at 14 months & .25 & .12 & $.25^{*}$ \\
\hline Father-toddler social toy play & .31 & .08 & $.43^{* * *}$ \\
\hline
\end{tabular}

${ }^{\text {a }}$ Adjusted $R^{2}=.32 ; F(2,62)=16.1, p=.000 ;{ }^{\mathrm{b}}$ Adjusted $R^{2}=.18 ; F(2,62)=8.0, p=.001 ;{ }^{\mathrm{c}}$ Adjusted $R^{2}$ $=.20 ; F(2,61)=8.7, p=.000$.

${ }^{+} p \leq .10{ }^{*} p \leq .05{ }^{* *} p \leq .01{ }^{* * *} p \leq .001$.

Table 3

Regression Models Predicting Developmental Outcomes at 36 Months

\begin{tabular}{|c|c|c|c|}
\hline & $B$ & $S E B$ & Beta \\
\hline \multicolumn{4}{|l|}{ Predicting cognitive development ${ }^{\mathrm{a}}$} \\
\hline MDI score at 14 months & .59 & .14 & $.48^{* * *}$ \\
\hline Father-toddler social toy play & 3.1 & 1.7 & $.21^{+}$ \\
\hline \multicolumn{4}{|l|}{ Predicting language development ${ }^{\mathrm{b}}$} \\
\hline MDI score at 14 months & .11 & .04 & $.35^{* *}$ \\
\hline Father-toddler social toy play & .86 & .47 & $.23^{+}$ \\
\hline \multicolumn{4}{|l|}{ Predicting emotional regulation ${ }^{\mathrm{c}}$} \\
\hline Emotional regulation at 14 months & .01 & .16 & .07 \\
\hline Father-toddler social toy play & .21 & .11 & $.24^{+}$ \\
\hline
\end{tabular}

${ }^{\mathrm{a}}$ Adjusted $R^{2}=.28 ; F(2,54)=11.8, p=.000 ;{ }^{\mathrm{b}}$ Adjusted $R^{2}=.17 ; F(2,54)=6.8, p=.001 ;{ }^{\mathrm{c}}$ Adjusted $R^{2}$ $=.03 ; F(2,59)=1.9, p=.16$.

$+p \leq .10{ }^{*} p \leq .05 .{ }^{* *} p \leq .01{ }^{* * *} p \leq .001$.

\section{DISCUSSION}

Overall, our results suggest that low-income fathers use toys to play with their children in ways that have been shown to influence early development in middle-class samples (Charman et al., 2001; Goldfield, 1987; Jacobson, 1981; Laasko et al., 1999; Mundy et al., 1992; Newland et al., 2001; Saxon et al., 2000). The fathers and toddlers in our study played together with toys, offering and showing the toys to each other or talking about the toys, responding to those initiations, and occasionally extending the interaction by returning the toys, imitating the other's actions with the 
RogGman et al.

toys, or continuing the conversation. For these mostly married Caucasian fathers living in a semi-rural area, the pattern of statistically significant correlations suggests that the more complex fathers' toy play interactions were with their two-year-olds, the better their children's cognitive, language, and emotional developmental outcomes. Further, the results show that the complexity of father-toddler toy exchanges, at age two, has a positive independent influence on toddler development beyond what can be expected from earlier development. This type of play is less likely, however, with fathers who are stressed or depressed. The differences between the EHS group and the comparison group in the quality of play suggest the potential for an early intervention program to influence father-toddler play, at least for a program like this one that targeted both father involvement and play interaction as part of their initial program design. The link shown here between father-toddler play and the early development of children from low-income families supports the value of interventions for infants and toddlers that are explicitly designed to target both fathers and play as part of their program objectives and strategies.

Our observations of father-toddler play provided a picture of fathers and toddlers making extended exchanges of objects and conversation as they played with toys together. The games fathers play with toddlers may be different from the games mothers play with them (Goldberg et al., 2002; Yogman, 1981), but when they play with their toddlers with toys, the complexity of their play seems to affect their children's early development just as with mothers (Newland et al., 2001). Furthermore, these social toy play interactions between fathers and toddlers were accompanied by other positive father behaviors. Fathers who had more complex social interactions with their toddlers and toys were also more likely to be generally supportive, as indicated by their sensitivity to the child's cues, cognitive stimulation, and positive regard during play. Positive interactions seem to go together, even though the moderate level of association indicates that supportiveness during play and social toy play complexity are indeed independent constructs. Both kinds of parent behavior have been shown in previous studies to be related to better child outcomes when they occur in play interactions with mothers (Black et al., 1999; Diener et al., 2003; Mundy et al., 1992; Newland et al., 2001). Supportiveness in toddler play with fathers also has been shown to provide support to early development (Black et al., 1999). Our results show that, in addition, complex social toy play interactions between fathers and toddlers are related to better developmental outcomes for young children.

The contributions of fathers to early development have been described in relation to the value of their play interactions (Grossman et al., 2002; Lamb, 1987, 1997; MacDonald \& Parke, 1986; Parke, 1981). The link found in this study from fathertoddler social toy play to children's developmental outcomes supports this position. Nevertheless, the kind of play seen in this study as influencing children's cognitive development, language development, and emotional regulation when it happened between toddlers and their fathers was the same kind of play that has been established in other studies as valuable for early development when it happens between toddlers and their mothers (Mundy et al., 1992; Newland et al., 2001). In our results, the influence of father-toddler social toy play on early development was so robust that it contributed to developmental outcomes beyond the contributions of earlier 
child functioning. Because this kind of father-toddler play appears to provide valuable support for early development, it is important to understand the factors that predict individual variability in the amount or quality of play interactions.

Complex social toy play was less likely with fathers who had reported symptoms of depression or stressful interactions with their children. When both depression and stress were included in analyses, however, only depression remained as a predictor of lower quality play. Previous studies have shown that depression interferes with the quantity of fathers' play with their infants (Goldberg et al., 2002; Lyons-Ruth et al., 2002), and our results indicate that it also interferes with the quality of their play. Fathers reporting more symptoms of depression were less likely to respond to or extend exchanges of toys and conversation when playing with a toddler. In other words, when fathers were more depressed, they did less complex sharing of toys during play with their toddlers. Thus, the play interactions of depressed fathers were less likely to offer toddlers the opportunities for shared meaning and turn taking that promote cognitive and social development (Mundy et al., 1992; Newland et al., 2001). EHS program enrollment moderated the effect of depression, however. When the EHS and comparison groups were considered separately, only the comparison group showed a statistically significant link between fathers' depression and play, while the EHS group, in contrast, showed no link at all. Evidently, family enrollment in the EHS program buffered the effect of fathers' depression on their social toy play interactions with their toddlers.

The complexity of father-toddler social toy play was greater for fathers from families enrolled in this EHS program that targeted fathers and play than for fathers in the comparison group. Although fathers were not randomly assigned to these groups, their families were, and the indication of a positive, albeit moderate, impact of family enrollment in this EHS program on father-toddler play interactions is important to note. Although other EHS programs might not affect fathering if they do not directly target fathers, this particular EHS program had targeted fathers for intervention efforts from the inception of the program. Program staff, as they began planning the program structure and design, expected that many fathers would be present in the lives of the infants and toddlers because of the high marriage rate in the local region. High father presence in local low-income families guided program staff to plan program strategies to involve fathers as a valuable resource for supporting children's early development. Fathers were invited to group activities, and home visits were scheduled, when possible, when fathers would be home. Despite these program efforts to involve fathers, however, this program, like other home-visiting programs, met with only moderate success, and not all fathers were present for home visits or in regular attendance at group activities (Peterson \& Luze, 2002; Roggman, Boyce, Cook, \& Cook, 2002). There were, nevertheless, other strategies this EHS program implemented to influence fathers. Fathers may have taken advantage of several other opportunities offered by the EHS program, such as special events and parties planned especially for fathers and families, family referrals to community resources, information provided to mothers, or written materials sent directly to fathers at home. These opportunities may have had direct or indirect effects on fathers that promoted positive social toy play with their toddlers. 
RogGman et al.

The influence of father-toddler play on children's cognitive and social development suggests potentially valuable future directions for early intervention. When fathers in this study, especially those in the EHS program group, played with their toddlers in complex social interactions with toys, the toddlers ended up with better scores on tests of cognitive competence, language acquisition, and emotional regulation, some of the most important aspects of early development that contribute to later school readiness. The patterns of results predicting developmental outcomes were more consistent in the EHS group than in the comparison group, suggesting that different factors may be contributing to child outcomes in the comparison group. For the EHS group, our findings suggest that by facilitating positive, supportive, developmentally appropriate play between fathers and infants, programs targeting infants and toddlers may be able to tap into the rich resource of father-child play interaction as a way to promote early development and later school success. Programs can target father-child play directly by planning more activities for fathers and children together, by scheduling more of their regular home visits directly with fathers, by planning play activities during home visits that are designed to elicit extended social interactions with objects, and by finding innovative ways to get more information to fathers about the importance of play in early development. Furthermore, early intervention programs may be able to support father-child play indirectly by assessing father psychosocial well-being, making appropriate referrals as needed, and promoting family mental health, strategies that may buffer the negative effects of father depression on play.

The primary limitations of this study are similar to the primary limitations of much of the research done on fathers. The original target of the research was the enrolled child and his or her family. For some families, no father was identified, no contact information was provided for contacting the father, or no agreement was obtained from the father to participate in the research. As a result, the sample included in this study was selective. The self-selection of fathers into the study meant that fathers who agreed to participate were more likely to be those who were functioning best. Although all of the families were low-income by federal poverty guidelines, the fathers who participated, compared to those who did not, were more likely to have completed high school and less likely to find parenting distressing. Also, the mostly married Caucasian fathers in this study differ from the majority of fathers in the larger EHS study who were less likely to be married and more likely to be of minority ethnicity. Compared to much of the research literature on fathers, also typically based on married Caucasian fathers, this sample offers data on a group whose children are at higher risk for poor developmental outcomes because they are in working-poor families. The range of father-toddler play quality in relation to child outcomes shows that father play made a difference to children in this sample of working, poor, two-parent families in a semi-rural area. The finding that EHS made a difference for father toy play at this local site is important, but other EHS programs might not affect fathering if father involvement and parent-child play interactions are not identified as primary program objectives. This particular EHS program emphasized both fathers and play and had an impact on fathering, albeit a modest effect, in spite of the challenges it faced as a new program trying to involve fathers. This effect is all the more interesting because it occurred in spite of the challenges. 
Many fathers were working full-time or more than one job, were unavailable when home visitors could schedule visits, were confused or put off by frequent turnover in the support staff for father involvement, or saw EHS as a program mostly for mothers and infants. Despite these challenges, fathers in families who had been in this EHS program showed more complexity in their play with their children compared to fathers in the comparison group. The importance of this impact is evident in the relation of the complexity of toy exchanges to child outcomes, even when controlling for earlier child development measures. Was it something the home visitor taught them? Something they saw their wives doing? Something they learned at social events with other fathers? We do not have the information to answer those questions, but the value of play for children's development, as shown in this and many other studies, and the modest but statistically significant impact of this EHS program on father-toddler play suggest that one strategy for enhancing early development may be to promote father-toddler play.

In conclusion, the results of this study suggest that how fathers play with their toddlers can affect children's development in positive ways. Furthermore, fathertoddler social toy play can be enhanced by a program such as EHS but hindered by a father's poor psychosocial well-being or lack of available time. Indeed, this EHS program appeared both to enhance fathers' play and to buffer the negative effects of fathers' poor psychosocial well-being. Fathers matter, not only by being present in the lives of infants and toddlers but also by being engaged in high-quality play with them. By playing with their infants and toddlers in ways that maintain interactive social exchanges, fathers provide opportunities that are important for early learning and development. These results show that father-child play matters even when fathers are playing, like mothers often do, by sharing toys and conversations with their toddlers - and the more they share, the better it is for children's development. These social toy play interactions offer a different experience than the more active and physical rough and tumble play of fathers with children. Social toy play between fathers and toddlers, involving sharing toys, responding to each other's initiations with toys, and extending those exchanges in games and conversation, appears to facilitate cognitive development, language development, and emotional regulation. Early development, in both cognitive and emotional domains, sets a foundation for later academic achievement. The results of this study, showing the contribution of father-toddler social toy play to this foundation, help expand our understanding of the potential value of active father involvement in children's lives during these critical early years.

\section{Note}

1. Four families are no longer in the sample, two due to death or adoption of the child, one that was never located after random assignment, and one moved out of the country permanently. 
RogGman et al.

\section{REFERENCES}

Abidin, R.R. (1990). Parenting stress index short form: Test manual. Department of Pediatrics. Charlottesville: The University of Virginia.

Administration for Children, Youth, \& Families. (2002). Making a difference in the lives of infants and toddlers and their families: The impacts of Early Head Start. Washington, DC: Department of Health and Human Services.

Albright, M.B., \& Tamis-LeMonda, C.S. (2002). Maternal depressive symptoms in relation to dimensions of parenting in low-income mothers. Applied Develop mental Science, 6, 24-34.

Bayley, N. (1993). Bayley scales of infant development, second edition: Manual. New York: The Psychological Corporation, Harcourt Brace \& Company.

Berlin, L.J., Brady-Smith, C., \& Brooks-Gunn, J. (2002). Links between childbearing age and observed maternal behaviors with 14-month-olds in the Early Head Start Research and Evaluation Project. Infant Mental Health Journal. Special Issue: Early Head Start, 23, 104-129.

Black, M.M., Dubowitz, H., \& Starr, R.H. (1999). African American fathers in low income, urban families: Development, behavior, and home environment of their three-year-old children. Child Development, 70, 967-978.

Carter, A.S., Garrity-Rokous, F.E., Chazan-Cohen, R., Little, C., \& Briggs-Gowan, M.J. (2001). Maternal depression and comorbidity: Predicting early parenting, attachment security, and toddler social-emotional problems and competencies. Journal of the American Academy of Child and Adolescent Psychiatry, 40, 18-26.

Charman, T., Baron-Cohen, S., Swettenham, J., Baird, G., Cox, A., \& Drew, A. (2001). Testing joint attention, imitation, and play as infancy precursors to language and theory of mind. Cognitive Development, 15, 481-498.

Clarke-Stewart, K.A. (1978). And daddy makes three: Father's impact on mother and young child. Child Development, 49, 466-478.

Crouter, A.C., Perry-Jenkins, M., Huston, T.L., \& McHale, S.M. (1987). Processes underlying father involvement in dual-earner and single-earner families. Devel opmental Psychology, 23, 431-440.

Darke, P.R., \& Goldberg, S. (1994). Father-infant interaction and parent stress with healthy and medically compromised infants. Infant Behavior and Development, $17,3-14$

Dickson, K.L., Walker, H., \& Fogel, A. (1997). The relationship between smile type and play type during parent-infant play. Developmental Psychology, 33, 925-933.

Diener, M.L., Nievar, M.A., \& Wright, C. (2003). Attachment security among mothers and their young children living in poverty: Associations with maternal, child, and contextual characteristics. Merrill-Palmer Quarterly, 49, 154-182.

DeVito, P.J., \& Karon, J.P. (1990). Pittsfield Chapter 1 Program. Parent-Child Home Program Longitudinal Evaluation. Pittsfield Public Schools.

Doherty, W.J., Kouneski, E.F., \& Erickson, M.F. (1998). Responsible fatherhood: A review and conceptual framework. Journal of Marriage and the Family, 60, 277-292. 
Fagan, J., \& Iglesias, A. (1999). Father involvement program effects on fathers, father figures, and their Head Start children: A quasi-experimental study. Early Childhood Research Quarterly, 14, 243-269.

Field, T. (1998). Maternal depression effects on infants and early interventions. Pre ventive Medicine: An International Journal Devoted to Practice \& Theory, 27, 200-203.

Field, T.M. (2000). Infants of depressed mothers. In S.L. Johnson \& A.M. Hayes (Eds.), Stress, coping, and depression (pp 3-22). Mahwah, NJ: Erlbaum.

Gerson, K. (1993). No man's land: Men's changing commitments to family and work. New York: Basic Books.

Goldberg, W.A., Clarke-Stewart, K.A., Rice, J.A., \& Dellis, E. (2002). Emotional energy as an explanatory construct for fathers' engagement with their infants. Parenting: Science and Practice, 2, 379-408.

Goldfield, B.A. (1987). The contributions of child and caregiver to referential and expressive language. Applied Psycholinguistics, 8, 267-280.

Graul, S.K., \& Zeece, P.D. (1990). Effects of play training of adults on the cognitive and play behavior of preschool children. Early Child Development and Care, 57, 15-22.

Grossman, F. K., Pollack, W.S., \& Golding, E. (1988). Fathers and children: Predicting the quality and quantity of fathering. Developmental Psychology, 24, 82-91.

Grossman, K., Grossman, K.E., Fremmer-Bombik, E., Kindler, H., ScheuererEnglisch, H., \& Zimmermann, P. (2002). The uniqueness of the child-father attachment relationship: Fathers' sensitive and challenging play as a pivotal variable in a 16-year longitudinal study. Social Development, 11, 307-331.

Hall, L.A., Williams, C.A., \& Greenberg, R.S. (1985). Supports, stress, and depressive symptoms in low-income mothers of young children. American Journal of Public Health, 75, 518-522.

Hoffman, Y.D., \& Drotar, D. (1991). The impact of postpartum depressed mood on mother-infant interaction: Like mother like baby? Infant Mental Health Journal, $12,65-80$.

Jacob, T., \& Johnson, S.L. (1997). Parent-child interaction among depressed fathers and mothers: Impact on child functioning. Journal of Family Psychology, 11, 391-409.

Jacob, T., \& Johnson, S.L. (2001). Sequential interactions in the parent-child communications of depressed fathers and depressed mothers. Journal of Family Psychology, 15, 38-52.

Jacobson, J.L. (1981). The role of inanimate objects in early peer interaction. Child Development, 52, 618-626.

Jameson, P.B., Gelfand, D.M., Kulcsar, E., \& Teti, D.M. (1997). Mother-toddler interaction patterns associated with maternal depression. Development and Psy chopathology, 9, 537-550.

Johnson, S.L., \& Jacob, T. (2000). Moderators of child outcome in families with depressed mothers and fathers. In S.L. Johnson \& A.M. Hayes (Eds.), Stress, coping, and depression (pp. 51-67). Mahwah, NJ: Erlbaum.

Laasko, M., Poikkeus, A.M., Eklund, K., \& Lyytinen, P. (1999). Social interactional behaviors and symbolic play competence as predictors of language development 
RogGMAN et al.

and their associations with maternal attention-directing strategies. Infant Behav ior and Development, 22, 541-556.

Laflamme, D., Pomerleau, A., \& Malcuit, G. (2002). A comparison of fathers' and mothers' involvement in childcare and stimulation behaviors during free-play with their infants at 9 and 15 months. Sex Roles, 47, 507-518.

Lamb, M.E. (1987). Predictive implications of individual differences in attachment. Journal of Consulting and Clinical Psychology, 55, 817-824.

Lamb, M.E. (1997). The development of father-infant relationships. In M.E. Lamb (Ed.), The role of the father in child development (3rd ed., pp. 104-120). New York: Wiley.

Leadbeater, B.J., Bishop, S.J., \& Raver, C.C. (1996). Quality of mother-toddler interactions, maternal depressive symptoms, and behavior problems in preschoolers of adolescent mothers. Developmental Psychology, 32, 280-288.

Levenstein, P., Levenstein, S., Shiminski, J.A., \& Stolzberg, J.E. (1998). Long-term impact of a verbal interaction program for at-risk toddlers: An exploratory study of high school outcomes in a replication of the Mother-Child Home Program. Journal of Applied Developmental Psychology, 19, 267-285.

Lindsey, E.W., Mize, J., \& Pettit, G.S. (1997). Differential play patterns of mothers and fathers of sons and daughters: Implications for children's gender role development. Sex Roles, 37, 643-661.

Lyons-Ruth, K., Wolfe, R., Lyubchik, A., \& Steingard, R. (2002). Depressive symptoms in parents of children under age three: Sociodemographic predictors, current correlates, and associated parenting behaviors. In N. Halfon \& K.T. McLearn (Eds.), Child rearing in America: Challenges facing parents with young children (pp. 217-259). New York: Cambridge University.

MacDonald, D., \& Parke, R.D. (1986). Parent-child physical play: The effect of sex and age of children and parents. Sex Roles, 15, 367-378.

Magill-Evans, J., \& Harrison, M.J. (2001). Parent-child interactions, parenting stress, and developmental outcomes at 4 years. Children's Health Care, 30, 135-150.

Mahoney, G., Wiggers, B., \& Lash S. (1996). Using a relationship-focused intervention program to enhance father involvement. Infant-Toddler Intervention, 6 , 295-308.

Malphurs, J., Field, T., Pelaez-Nogueras, M., \& Martinez, A. (1997). Moderately dysphoric mothers behave more positively with their infants after completing the BDI. Infant Mental Health Journal, 18, 394-405.

Mundy, P., Kasari, C., \& Sigman, M. (1992). Nonverbal communication, affective sharing, and intersubjectivity. Infant Behavior and Development, 15, 377-381.

Myers, B.J. (1982). Early intervention using Brazelton training with middle-class mothers and fathers of newborns. Child Development, 53, 462-471.

Newland, L.A., Roggman, L.A., \& Boyce, L.K. (2001). The development of social toy play and language in infancy. Infant Behavior and Development, 24, 1-25.

Nugent, J.K. (1991). Cultural and psychological influences on the father's role in infant development. Journal of Marriage and the Family, 53, 475-485.

Parke, R.D. (1981). Fathers. Cambridge: Cambridge University. 
Peterson, C., \& Luze, G. (2002, June). Relationships between home visiting inter vention and outcomes. Head Start's National Research Conference, Washington, DC: Head Start Bureau, ACYF.

Pettit, G.S., Brown, E.G., Mize, J., \& Lindsey, E. (1998). Mothers' and fathers' socializing behaviors in three contexts: Links with children's peer competence. Merrill-Palmer Quarterly, 44, 173-193.

Pfannenstiel, A.E., \& Honig, A.S. (1995). Effects of a prenatal "Information and Insights about Infants" program on the knowledge base of first-time low education fathers one month postnatally. Early Child Development and Care, 111, 87-105.

Radloff, L.S. (1977). The CES-D Scale: A self-report depression scale for research in the general population. Applied Psychological Measurement, 1, 385-401.

Raikes, H.H., \& the EHS Research Consortium Father Studies Workgroup. (2000, April). Father involvement in Early Head Start: Listening to the voices of fathers, mothers, and program staff. National Head Start Association, Washington, DC.

Roberts, P. (1998). Fathers' time. In E.N. Junn \& C.J. Boyatzis (Eds.), Child growth and development, Annual editions, 98/99 (pp. 146-152). Guilford, CT: Dushkin.

Roggman, L.A., Benson, B., \& Boyce, L.K. (1999). Fathers with infants: Knowledge and involvement in relation to psychosocial functioning and religion. Infant Mental Health, 20, 257-277.

Roggman, L.A. \& Boyce, L.K., \& Cook, J. (2001). Widening the lens: Viewing fathers in infants' lives. In H.E. Fitzgerald, K.H. Karraker, \& T. Luster (Eds.) Infant development: Ecological perspectives (pp. 193-220). New York: Routledge Falmer.

Roggman, L.A., Boyce, L.K., Cook, G.A., \& Cook, J. (2002). Getting dads involved: Predictors of father involvement in Early Head Start and with their children. Infant Mental Health Journal, 23, 62-78.

Roopnarine, J.L., \& Mounts, N.S. (1998). Mother-child and father-child play. Early Child Development and Care, 20, 157-169.

Saxon, T.F., Colombo, J., Robinson, E.L., \& Frick, J.E. (2000). Dyadic interaction profiles in infancy and preschool intelligence. Journal of School Psychology, $38,9-25$.

Shannon, J.D., Tamis-LeMonda, C.S., London, K., \& Cabrera, N. (2002). Beyond rough and tumble: Low-income fathers' interactions and children's cognitive development at 24 months. Parenting: Science and Practice, 2, 77-104.

Spanier, G.B. (1987). Dyadic Adjustment Scale. In K. Corcoran \& J. Fischer (Eds.), Measures for clinical practice: A sourcebook (pp. 424-427). New York: Free Press.

Summers, J.A., Raikes, H., Butler, J. Spicer, P., Pan, B., Shaw, S., Langager, M., McAllister, C., \& Johnson, M.K. (1999). Low income fathers' and mothers' perceptions of the father role: A qualitative study in four Early Head Start communities. Infant Mental Health Journal Special Issue: Fathers and Infants, 20, 291-304.

Tamis-LeMonda, T.S., \& Bornstein, M.H. (1989). Habituation and maternal encouragement of attention in infancy as predictors of toddler language, play, and representational competence. Child Development, 60, 738-751. 
RogGman et al.

Tamis-LeMonda, T.S., \& Bornstein, M.H. (1990). Language, play, and attention at one year. Infant Behavior and Development, 13, 85-98.

Wachs, T., Uzgiris, L., \& Hunt, J. (1971). Cognitive development in infants of different age levels and from different environmental backgrounds. Merrill-Palmer Quarterly, 17, 283-317.

Yogman, M. (1981). Games fathers and mothers play with their infants. Infant Men tal Health Journal, 2, 241-248.

Yogman, M.W. (1994). Observations on the father-infant relationship. In S.H. Cath, A.R. Gurwitt, \& J.M. Ross (Eds.), Father and child: Developmental and clini cal perspectives (pp. 101-122). Hillsdale: The Analytic Press.

Yogman, M.W., Kindlon, D., \& Earls, F. (1995). Father involvement and cognitive/behavioral outcomes of preterm infants. Journal of the American Academy of Child and Adolescent Psychiatry, 34, 58-66. 
Copyright of Fathering: A Journal of Theory, Research, \& Practice about Men as Fathers is the property of Men's Studies Press and its content may not be copied or emailed to multiple sites or posted to a listserv without the copyright holder's express written permission. However, users may print, download, or email articles for individual use. 